\title{
A SOLUBILITY ENHANCEMENT OF ACECLOFENAC BY NEW CRYSTALLIZATION TECHNIQUE
}

\author{
CHETHAN PATEL DN*, SHRENATH A
}

Department of Pharmaceutics, SJM College of Pharmacy, Chithradurga, Karnataka, India. Email: chethanpatel2@gmail.com

Received: 15 September 2021, Revised and Accepted: 17 December 2021

\begin{abstract}
Objective: The present work aim was "A solubility enhancement of aceclofenac by new crystallization technique." Aceclofenac is non-steroidal antiinflammatory drug comes under bio-pharmaceutics classification system Class II with low solubility and high permeability. The aim of the study was to study the solubility and dissolution rate of the pure drug and prepared crystals at different temperature.
\end{abstract}

Methods: Crystal of aceclofenac was prepared by antisolvent sonocrystallization technique.

Results: A different crystal was prepared by Antisolvent sonocrystallization technique. The effect of solvents, temperature, and sonication was investigated. All the formulation was studied the dissolution behavior, MDT, \%DE, and solid state characterization such as differential scanning calorimetry (DSC), X-ray diffraction (XRD), and scanning electron microscopy (SEM).

Conclusion: The solubility and dissolution rate of the prepared crystals were significantly higher than pure drug. The prepared crystals in ethanol at temperature $60^{\circ} \mathrm{C} \pm 1^{\circ} \mathrm{C}$ showed the highest of the solubility of drug at $60 \mathrm{~min}$. Among the prepared aceclofenac, crystals at 60 were showed better results with respect to MDT and \%DE when compared to preparation of crystals at $10^{\circ} \pm 1^{\circ} \mathrm{C}$ and $25 \pm 1^{\circ} \mathrm{C}$. DSC studies showed that there was no appreciable change in the melting endotherm of prepared crystals compared to that of pure drug. Powder XRD of prepared crystals at different temperature shows increases intensity of peaks compared to pure drug. SEM studies indicated that prepared crystals at different temperature using sonication shows are sharp needle in shape with crystalline surface compared to pure drug. The results indicate that antisolvent sonocrystallization serves as a successful strategy for enhancing poorly water soluble drug.

Keywords: Aceclofenac, Sonocrystallization, Antisolvent, Solubility, Dissolution.

(C) 2022 The Authors. Published by Innovare Academic Sciences Pvt Ltd. This is an open access article under the CC BY license (http://creativecommons.org/ licenses/by/4.0/) DOI: http://dx.doi.org/10.22159/ajpcr.2022v15i2.43134. Journal homepage: https://innovareacademics.in/journals/index.php/ajpcr

\section{INTRODUCTION}

Oral drug delivery is the most convenient cost-effectiveness and flexibility in the design of dosage form. The oral bioavailability depends on several factors including aqueous solubility, drug permeation, dissolution rate, and first pass metabolism; the main reason for poor bioavailability is poor solubility and low permeation. The major challenge with the design of oral dosage forms with their poor bioavailability. Especially for Class-II substances according to the bio-pharmaceutics classification system, the bioavailability may be enhanced by increasing the solubility and dissolution rate of the drug [1]. The main possibility for improving bioavailability is to increase the surface area available for dissolution rate by decreasing the particle size of the solid compound. Particle design techniques are developed with the intention to modify the physicochemical, micromeritics, and biopharmaceutical properties of the drug [2].

There are several approaches available to enhance the solubility of poorly water drugs. Techniques for solubility enhancement are micronization, nanonization, cosolvency, $\mathrm{pH}$ adjustment, sonocrystallization, supercritical fluid process, and inclusion complexation, liquisolid method. Sonocrystallization is one of the techniques used to develop the solubility of the poorly soluble drugs. In this technique, ultrasound is used as an energy source for crystallization. Crystallization of drugs to produce high purity powder with will defined particle size distribution, crystal habit, crystal form, surface nature, and application of ultrasound energy to control then of crystallization process [3]. Ultrasound to crystallization process as result is narrow of metastable one width, narrow of particle size distribution, avoiding crash of crystallization, highly repeatable and predictable crystallization, and polymorph control [4].

\section{MATERIALS}

Aceclofenac was received as a gift sample from the Karnataka antibiotics and pharmaceuticals limited, Bengaluru, ethanol and acetone obtained Standard Deviation (SD) fine chemicals, Mumbai, India, distilled water was collected in house.

\section{METHODS}

\section{Preparation crystals}

Antisolvent method

Crystal of aceclofenac was prepared by antisolvent crystallization technique using three solvent systems an antisolvent. Ethanol and acetone were selected as solvents and water was used as antisolvent. A solution of aceclofenac (100 mg) in $5 \mathrm{ml}$ of acetone or ethanol was prepared in a beaker. Moreover, water as anti-solvent is taken in another beaker. The mixture of clear aceclofenac solution is added drop-wise to beaker containing antisolvent until precipitations occur. The mixture is allowed to stand for $10 \mathrm{~min}$ and finally filtered the solution using Whatmann filter paper [5]. The collected powder is dried at $37.5^{\circ} \mathrm{C}$ for $24 \mathrm{~h}$.

\section{Crystallization under ultrasonication in antisolvent}

Crystal of aceclofenac was prepared by antisolvent crystallization technique by applying an ultrasonication. It involved a solvent and antisolvent system. Ethanol and acetone were selected as solvent and water as anti-solvent. A solution of aceclofenac $(100 \mathrm{mg})$ in $5 \mathrm{ml}$ of acetone or ethanol was prepared. The clear aceclofenac solution was added drop-wise to a beaker containing antisolvent (10 ml water). Immediately, ultrasound energy was applied by ultrasonication at with nine duty cycle and $50 \%$ power for a duration of $5 \mathrm{~min}$. After the sonication, filter the solution and dry at room temperature [6]. 
Evaluation of pure drug and prepared crystal

\section{Solubility studies}

Excess amount of drug or crystals obtained after sonocrystallization was added to $10 \mathrm{ml}$ volumetric flask containing distilled water, $0.1 \mathrm{~N} \mathrm{HCl}$ $(\mathrm{pH} 1.2)$ or phosphate buffer solution $(\mathrm{pH}$ 6.8). The volumetric flasks were agitated on a rotary shaker for $48 \mathrm{~h}$ at $100 \mathrm{rpm}$ maintained at room temperature. At the end of $48 \mathrm{~h}$, the mixture was filtered, filtrate was suitably diluted and analyzed at $275 \mathrm{~nm}$ using ultraviolet (UV)visible spectrophotometer (UV-1601, Simadzu, Japan) [7].

\section{In vitro drug release studies}

The in vitro drug dissolution study of pure drug or crystals was performed using eight station dissolution test apparatus (TDT-08L, Electrolab, India) with a paddle speed of $50 \mathrm{rpm}$. Dissolution medium consisted of $900 \mathrm{ml}$ of either $0.1 \mathrm{~N} \mathrm{HCl} \mathrm{(pH} \mathrm{1.2),} \mathrm{phosphate} \mathrm{buffer}$ solution ( $\mathrm{pH} 6.8$ ), or water maintained at $37 \pm 0.5^{\circ} \mathrm{C}$. At a predetermined time intervals, an aliquot was withdrawn and replenished with fresh medium. Amount of dissolved drug in each aliquot was measured on a UV-visible spectrophotometer (UV-1601, Shimadzu, Japan) at $275 \mathrm{~nm}$ using suitable blank. All the trials were conducted in triplicate and the average $( \pm \mathrm{SD})$ reading was noted [8].

\section{Model independent analysis}

Dissolution efficiency

Dissolution efficiency is used to translate the profile difference into a single value. Dissolution efficiency was calculated using following equation.

$$
\mathrm{DE} \%=\frac{\int_{0}^{\mathrm{t}} y \mathrm{dt}}{y_{100}} t \times 100
$$

Where, $\mathrm{y}$ is the drug percent dissolved at time $\mathrm{t}$.

\section{Mean dissolution time}

Mean dissolution time represents the mean time for drug molecules to completely dissolve. It is used to characterize the drug release rate from a dosage form and indicates the drug release retarding efficiency of the polymer. MDT was calculated using the following equation.

$$
M D T=\frac{\sum_{\mathrm{i}=1}^{\mathrm{i}=\mathrm{n}} t_{\text {mid }} \times \Delta M}{\sum_{\mathrm{i}=1}^{\mathrm{i}=\mathrm{n}} \Delta M}
$$

Where " $i$ " is the dissolution sample number, " $n$ " is the number of dissolution sample time, "tmid" is the time at the midpoint between " $\mathrm{i}$ " and " $\mathrm{i}-1$," and " $\Delta \mathrm{M}$ " is the amount of drug dissolved between " $\mathrm{i}$ " and "i-1" [9].

\section{Differential scanning calorimetric analysis}

The samples of drug and the prepared crystals were taken in aluminum pan, sealed with aluminum cap, and kept under nitrogen purging (atmosphere). The samples were scanned from 0 to $300^{\circ} \mathrm{C}$ with the scanning rate of $10^{\circ} \mathrm{C}$ rise/min using differential scanning calorimeter.

\section{Scanning electron microscopy (SEM)}

The samples of drug and the prepared crystals were sputter coated using an electrically conducting metal such as gold onto a drug and crystals (Sputter coating equipment details). Then, the shape and surface topography of drug and crystals was observed through a SEM (TESCAN VEGA3 LMU).

\section{Powder X-ray diffraction (PXRD)}

The PXRD patterns were recorded using an X-ray diffractometer (PW3071/xx Bracket), with copper as anode material and crystal graphite monochromator operated at a voltage of $30 \mathrm{~mA}, 40 \mathrm{kV}$. The samples were analyzed in the $2 \theta$ angle range of 7-60 with reproducibility of $0.001^{\circ} \mathrm{C}$ for pure drug and prepared crystals. The position and intensities of diffraction peaks were considered for the identification and comparison of crystallinity of the drug and prepared crystals [10].

\section{RESULTS AND DISCUSSION}

Evaluation of drug crystals and prepared crystals at different temperature

The results for solubility studies of pure aceclofenac in distilled water, $0.1 \mathrm{~N} \mathrm{HCl}$, and phosphate buffer solution (pH 6.8) are show in Fig. 1. It was found solubility of drug in water, $0.1 \mathrm{HCl}$, and phosphate buffer $\mathrm{pH}$ (6.8) to be $0.0008 \pm 0.00145 \mathrm{mg} / \mathrm{ml}, 0.0680 \pm 0.877 \mathrm{mg} / \mathrm{ml}$, and $0.1097 \pm 0.0699 \mathrm{mg} / \mathrm{ml}$. As per this result, aceclofenac shows very less solubility in water compared to $0.1 \mathrm{~N} \mathrm{HCl}$ and phosphate buffer. The data of solubility study of crystals prepared at different temperature are shown in Tables 3 and 4. The solubility of drug increased with use of solvent (ethanol and acetone) and it was observed that solubility was influenced by ultrasonication as shown in Table 3, the solubility was influenced the solvent and the drug solubility increased with use of acetone at all the temperature used for crystallization. The solubility data indicate that by applying ultrasonication during

Table 1: Composition of aceclofenac crystals

\begin{tabular}{lll}
\hline Formulation & F1 & F2 \\
\hline Aceclofenac & $100 \mathrm{mg}$ & $200 \mathrm{mg}$ \\
Ethanol & $5 \mathrm{ml}$ & $10 \mathrm{ml}$ \\
Acetone & $5 \mathrm{ml}$ & $10 \mathrm{ml}$ \\
Water & $15 \mathrm{ml}$ & $15 \mathrm{ml}$ \\
\hline
\end{tabular}

Table 2: Effect of variables on formulation of crystals of aceclofenac by antisolvent crystallization technique

\begin{tabular}{lll}
\hline Parameter & Variables & Observations \\
\hline Choice of solvent & Ethanol & Drug freely soluble \\
& Acetone & Drug freely soluble \\
& Dichloromethane & Drug freely soluble \\
& Chloroform & Drug insoluble \\
Choice of antisolvent & Water+ethanol & Easy miscible \\
& Water+acetone & Easy miscible \\
& Waterdichloromethane & Immiscible \\
& Water+chloroform & Immiscible \\
Amount of antisolvent* & $5 \mathrm{ml}$ & Not immediately \\
& $15 \mathrm{ml}$ & Immediately \\
& $20 \mathrm{ml}$ & Not immediately \\
& $30 \mathrm{ml}$ & Not immediately \\
\hline
\end{tabular}

*Precipitation

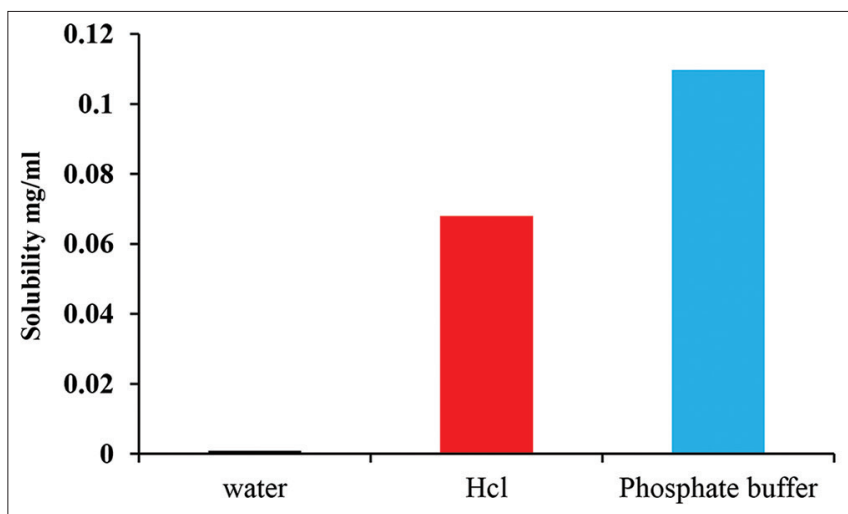

Fig. 1: Comparison of solubility of aceclofenac in distilled water, $0.1 \mathrm{~N} \mathrm{HCl}$, and phosphate buffer solution ( $\mathrm{pH} 6.8$ ) 
Table 3: Solubility study of prepared crystals at different temperature

\begin{tabular}{llrl}
\hline Formulation & \multicolumn{3}{l}{ Solubility in water $(\mathbf{m g} / \mathbf{m l})$} \\
\cline { 2 - 4 } & $\boldsymbol{*}^{\mathbf{1}} \mathbf{0}^{\circ} \mathbf{\pm} \mathbf{1}^{\circ} \mathbf{C}$ & $\boldsymbol{2 5}^{\circ} \pm \mathbf{1}^{\circ} \mathbf{C}$ & ${ }^{*} \mathbf{6 0}^{\circ} \pm \mathbf{1}^{\circ} \mathbf{C}$ \\
\hline Aceclofenac & $0.10 \pm 0.06$ & $0.10 \pm 0.06$ & $0.11 \pm 0.07$ \\
E1 & $1.42 \pm 0.04$ & $0.99 \pm 0.04$ & $0.61 \pm 0.02$ \\
E2 & $1.41 \pm 0.04$ & $1.87 \pm 0.02$ & $2.90 \pm 0.06$ \\
A1 & $1.01 \pm 0.07$ & $1.44 \pm 0.06$ & $1.60 \pm 0.05$ \\
A2 & $2.01 \pm 0.01$ & $1.90 \pm 0.04$ & $2.81 \pm 0.04$ \\
\hline
\end{tabular}

*Temperature of crystallization Values are mean \pm SD, $n=3$

Table 4: Crystals prepared by ultrasonication at $25^{\circ} \mathrm{C} \pm 1^{\circ} \mathrm{C}$

\begin{tabular}{ll}
\hline Formulation & Solubility in water $(\mathbf{m g} / \mathbf{m l})$ \\
\hline E1 & $0.99 \pm 0.04$ \\
E2 & $1.91 \pm 0.02$ \\
A1 & $1.44 \pm 0.06$ \\
A2 & $1.86 \pm 0.02$ \\
\hline
\end{tabular}

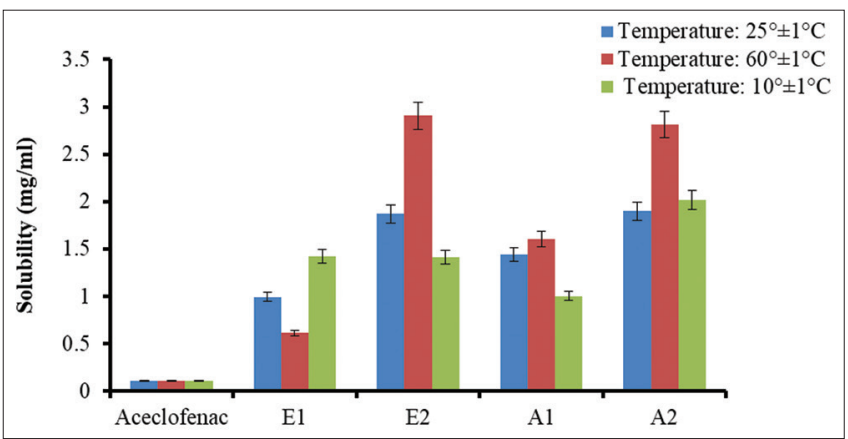

Fig. 2: Comparison of solubility study profile of aceclofenac and different crystals in distilled water

crystallization will lead to enhancement solubility of the prepared crystals. The prepared aceclofenac crystals at different temperature condition were subjected to dissolution study, at end of $60 \mathrm{~min}$ $2.38 \pm 0.01 \%$ of drug was dissolved, the prepared crystals at $10^{\circ} \mathrm{C} \pm 1^{\circ} \mathrm{C}$ using ethanol and acetone show dissolution of $22.91 \pm 3.55$ and $19.05 \pm 0.69$ dissolution at $60 \mathrm{~min}$, the $\%$ of drug dissolved increased to $90.29 \pm 1.43$ and $49.44 \pm 6.50$ for the crystals prepared at $10^{\circ} \mathrm{C} \pm 1{ }^{\circ} \mathrm{C}$ with ultrasonication. Similar trend is observed for crystals prepared $25^{\circ} \pm 1^{\circ} \mathrm{C}$ and $60^{\circ} \pm 1^{\circ} \mathrm{C}$; the study showed that temperature of crystals is critical parameter as influence solubility and dissolution of the prepared crystals.

Evaluation of crystals prepared with sonication by probe and bath sonicator

The solubility and dissolution of crystals prepared are shown in Figs. 3 and 4. The solubility of prepared crystals E1 in distilled water was found to be $0.994 \pm 0.049 \mathrm{mg} / \mathrm{ml}$ and E2 by applying probe sonication was found to be $1.912 \pm 0.017 \mathrm{mg} / \mathrm{ml}, \mathrm{A} 1$ in distilled water was found to be $1.441 \pm 0.062 \mathrm{mg} / \mathrm{ml}$, and A2 by applying sonication was found to be $1.866 \pm 0.020 \mathrm{mg} / \mathrm{ml}$. The solubility of prepared crystals under bath sonication was found to be $1.82 \pm 0.01$ and $1.40 \pm 0.03 / \mathrm{mL}$, respectively, prepared in ethanol and acetone, the data show substantial influence of sonication process on solubility of prepared crystals, among the method crystals prepared under sonication using probe sonicator and bath sonicator as shown in Figs. 3 and 4, solubility compared to crystals prepared by bath sonication. Dissolution behavior of pure aceclofenac and prepared crystals in different temperature was studied using distilled water as dissolution medium. The amount of pure aceclofenac dissolved in distilled water was found to be $2.38 \%$ at $60 \mathrm{~min}$. Dissolution

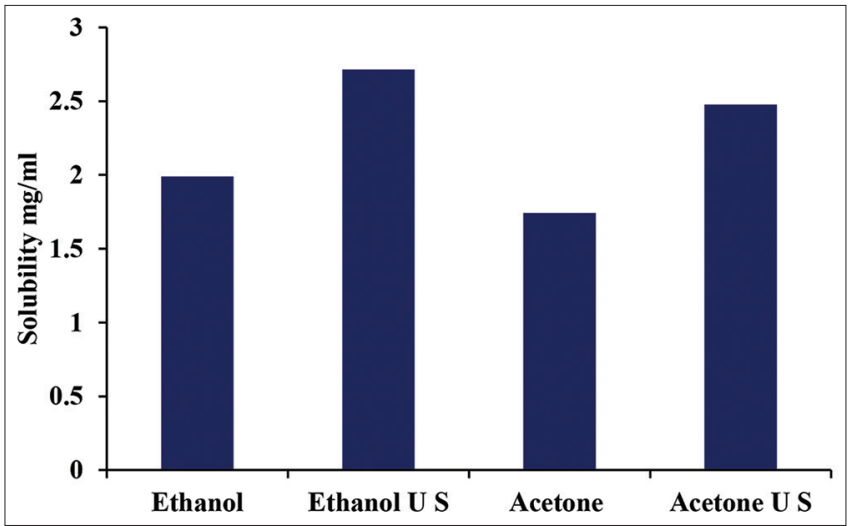

Fig. 3: Comparison of solubility study profile of different prepared crystals in $25^{\circ} \mathrm{C} \pm 1^{\circ} \mathrm{C}$ by bath sonicaton

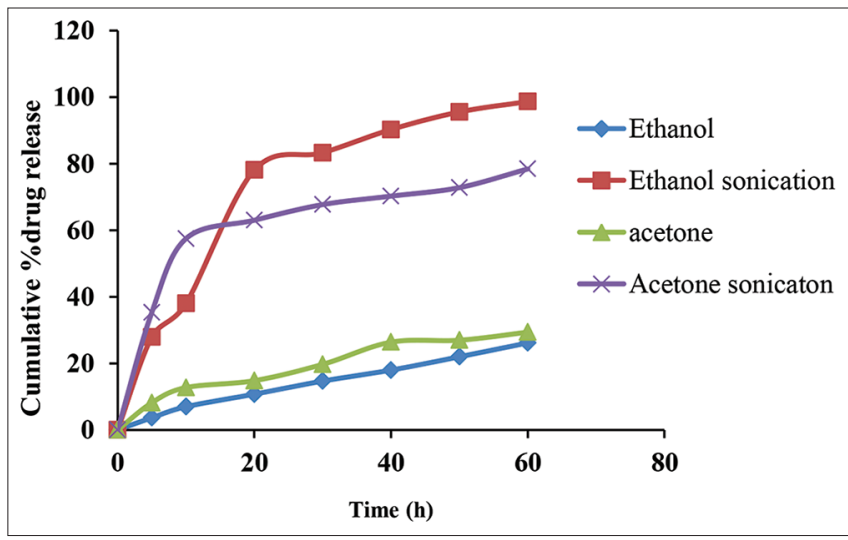

Fig. 4: Comparison of in vitro dissolution profile of different crystals prepared by bath sonicator

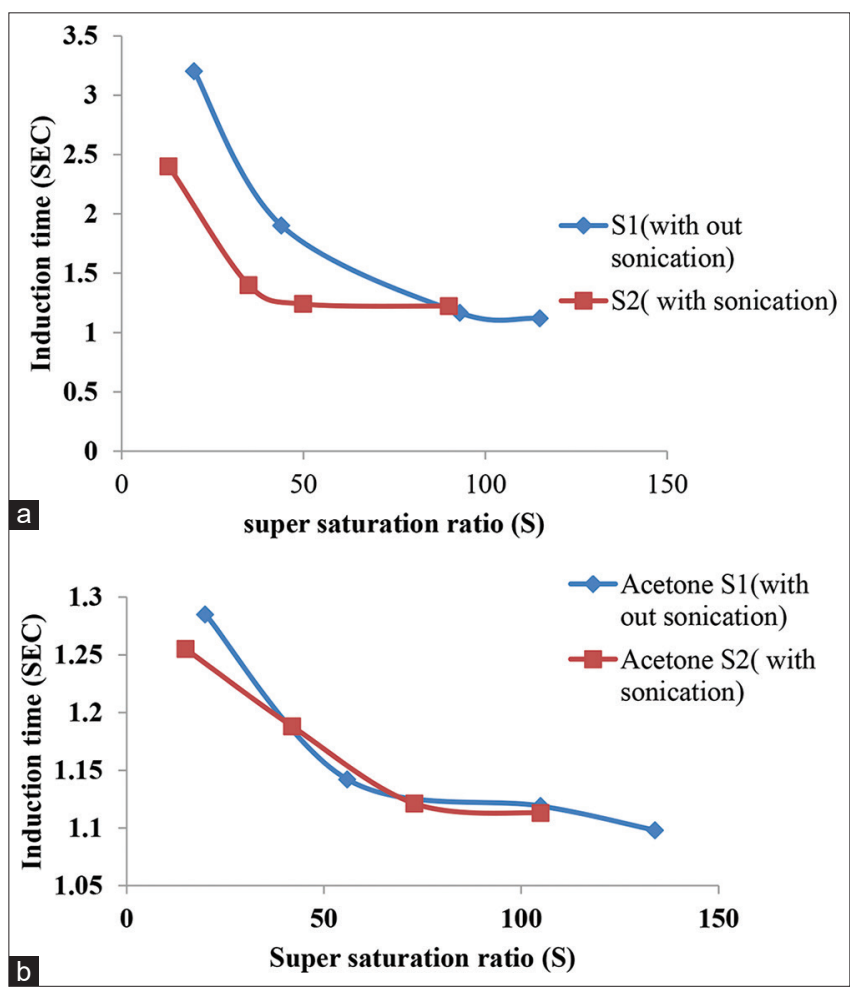

Fig. 5: Comparison of induction time of (a) crystals prepared with ethanol and (b) crystals prepared with acetone as solvent 
behavior of prepared the crystals by probe and bath sonicator was studied using distilled water as dissolution medium. The in vitro dissolution profile data of prepared crystals E1, E2, A1, and A2 are shown in Fig. 4. The in vitro cumulative \% drug dissolved of the prepared crystal for E1, E2, A1, and A2 was found to be $51.71 \pm 13.25$,
$83.85 \pm 3.25,48.66 \pm 12.57$, and $68.30 \pm 4.93 \%$ at $60 \mathrm{~min}$, respectively, among the dissolution data of prepared crystals by probe sonication, it was observed that crystals prepared using ethanol as show highest dissolution, similarly the dissolution data show that at end of $60 \mathrm{~min}$ $51.71 \pm 13.25,83.85 \pm 3.25,48.66 \pm 12.57$, and $68.30 \pm 4.95$, respectively,

Table 5: Model independent analysis of dissolution data

\begin{tabular}{|c|c|c|c|c|c|c|}
\hline \multirow[t]{3}{*}{ Formulation } & \multicolumn{6}{|c|}{ Temperature of crystallization } \\
\hline & \multicolumn{2}{|l|}{$10^{\circ} \mathrm{C} \pm 1^{\circ} \mathrm{C}$} & \multicolumn{2}{|l|}{$25^{\circ} \mathrm{C} \pm 1^{\circ} \mathrm{C}$} & \multicolumn{2}{|l|}{$60^{\circ} \mathrm{C} \pm 1^{\circ} \mathrm{C}$} \\
\hline & MDT (min) & $\% \mathrm{DE}_{60 \mathrm{~min}}$ & MDT (min) & $\% \mathrm{DE}_{60 \min }$ & MDT (min) & $\% \mathrm{DE}_{60 \mathrm{~min}}$ \\
\hline Aceclofenac & 40 & 32.40 & 40 & 32.40 & 40 & 32.40 \\
\hline E1 & 25 & 57.98 & 24 & 58.15 & 22 & 63.18 \\
\hline $\mathrm{E} 2$ & 23 & 60.82 & 22 & 62.36 & 21 & 64.36 \\
\hline $\mathrm{A} 1$ & 28 & 52.54 & 26 & 55.52 & 23 & 61.34 \\
\hline
\end{tabular}

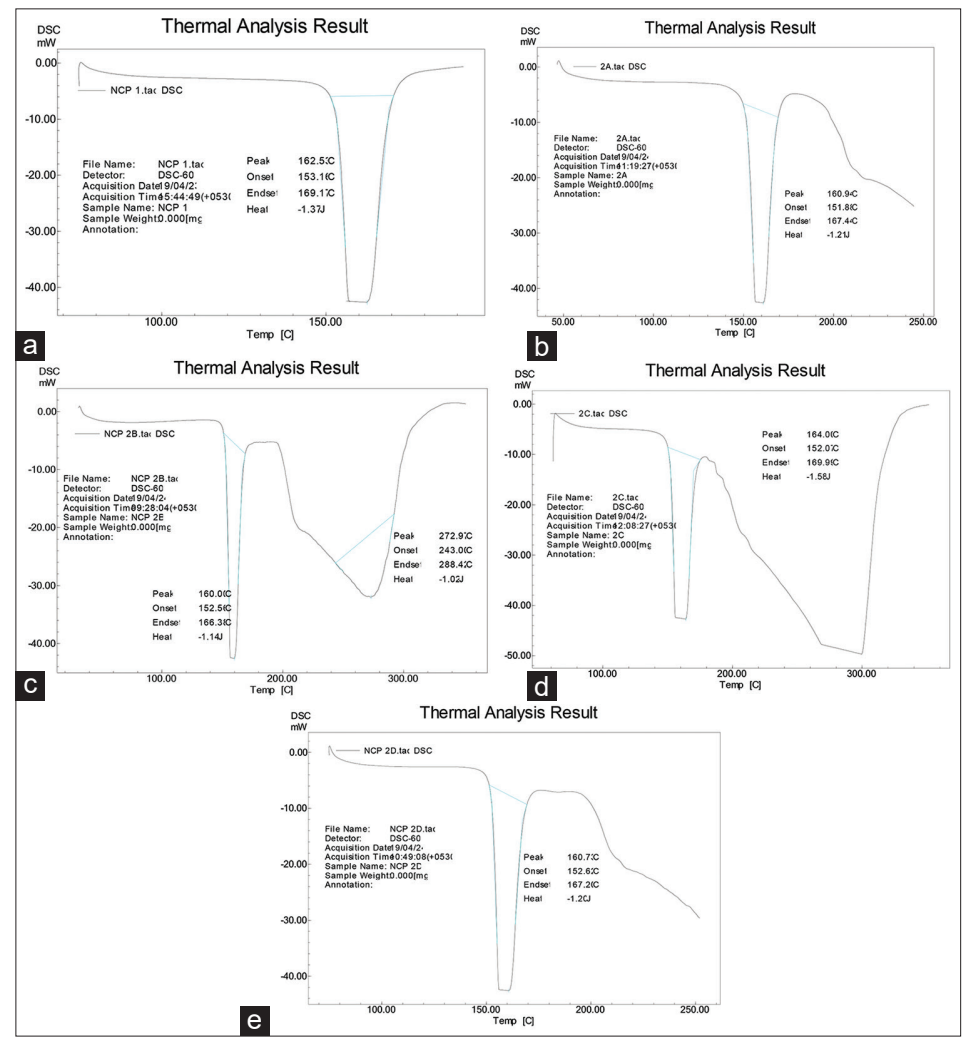

Fig 6: Differential scanning calorimetry thermograms of (a) aceclofenac, (b) crystals prepared by using ethanol, (c) crystals prepared in ethanol by ultrasonication, (d) crystals prepared in acetone and (e )crystals prepared in acetone by using sonication.

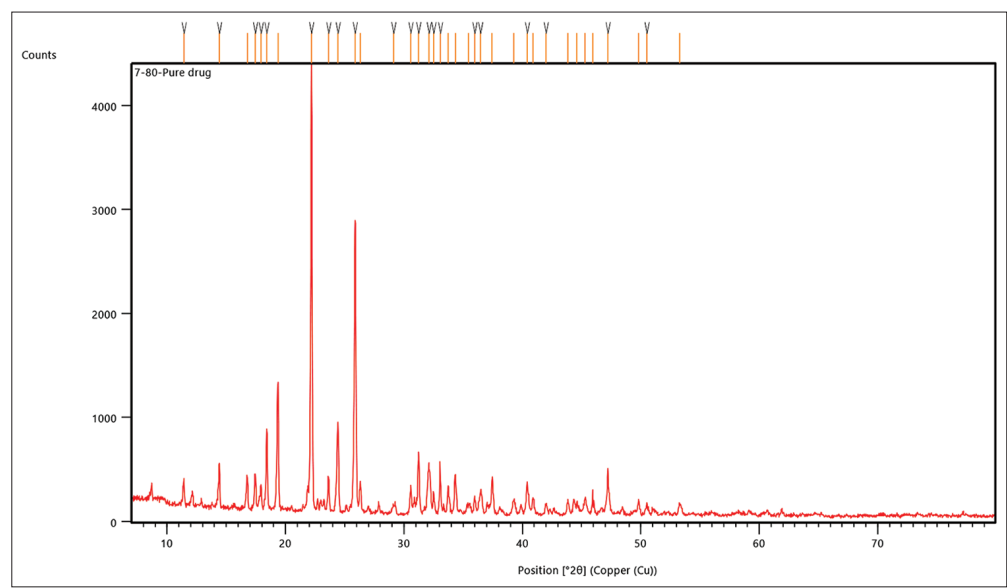

Fig. 7: Powder X-ray diffraction of aceclofenac 
from B E1, B E2, B A1, and BA2 prepared crystals under bath sonication similar to the data observed for probe sonicator crystals prepared using ethanol as solvent and bath sonication as shown highest solubility.

\section{Evaluation of the induction time of the prepared crystals} Effect of ultrasonication on the induction time of prepared crystals The induction time of prepared crystals in (ethanol and acetone) at different supersaturation levels was studied at $25^{\circ} \mathrm{C} \pm 1^{\circ} \mathrm{C}$ as shown in Fig. 5. The supersaturation is the ratio of the aceclofenac

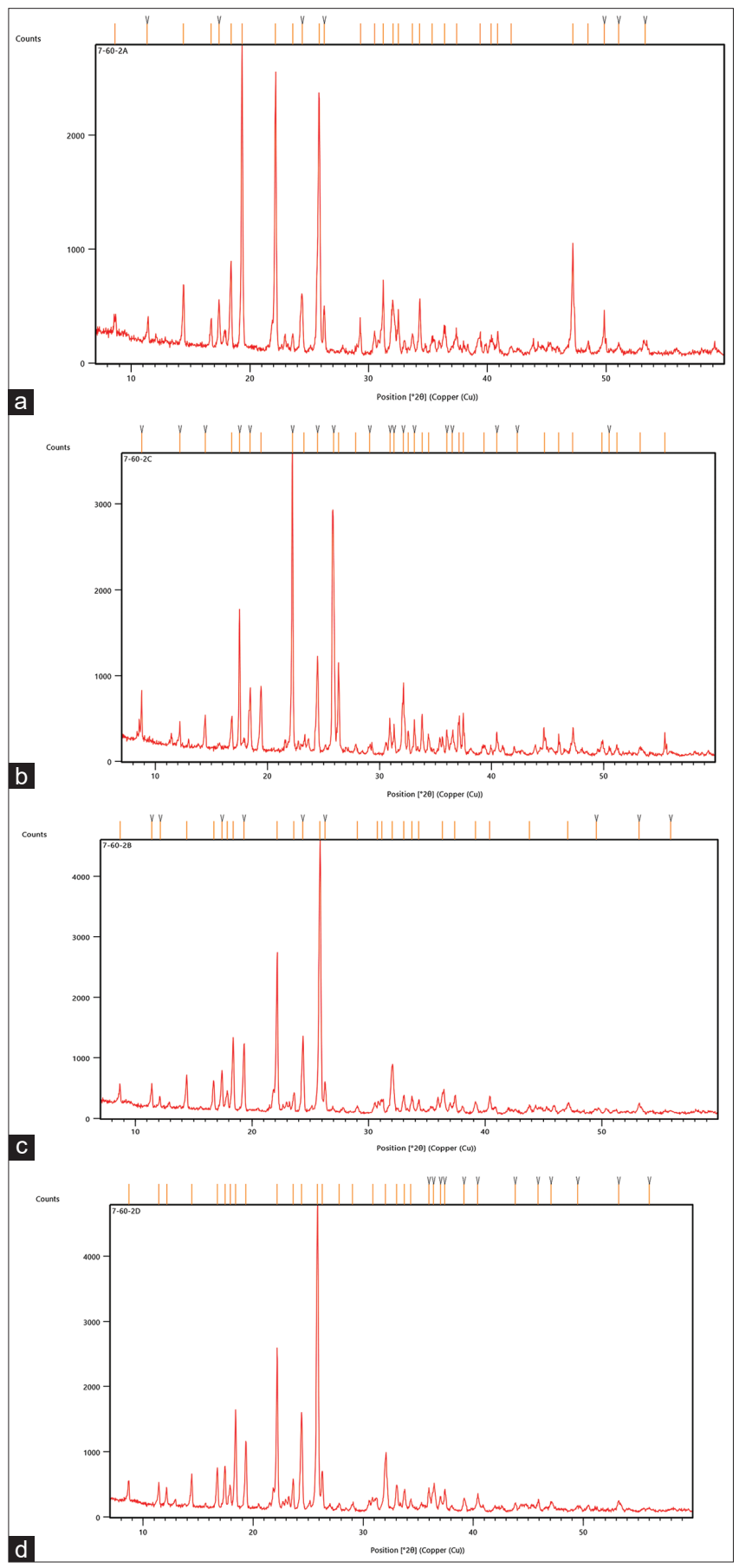

Fig. 8: Powder X-ray diffraction of (a) crystals prepared using ethanol, (b) crystals prepared using acetone, (c) crystals prepared in ethanol by sonication, and (d) crystals prepared in acetone by sonication concentration to its solubility under the $25^{\circ} \mathrm{C} \pm 1{ }^{\circ} \mathrm{C}$, the induction time of prepared crystals decreases when supersaturation increases, ultrasonication reduces the induction time significantly, especially at high supersaturation levels. At a supersaturation over 3.20, the induction time becomes reduces when ultrasonication is used. At the difference level of supersaturation, the induction time is much shorter with ultrasonication than with the traditional stirring method. The ultrasonication reduces the solution's viscosity and surface tension, and ultrasonic cavitation intensifies collisions between solute molecules, leading to the formation of crystal nuclei.

\section{Model independent analysis}

MDT and \%DE were determined for the drug and prepared crystals as shown in the Table 5 and the values varied between 18 and $40 \mathrm{~min}$ and 32.34-69.62\%, respectively. The model independent parameters calculated for different crystals prepared under various conditions further supports, the influence of temperature, and sonication on solubility and dissolution. Aceclofenac crystals prepared at $60^{\circ} \mathrm{C} \pm 1^{\circ} \mathrm{C}$ showed lower MDT and higher \%DE compared to pure aceclofenac. This supports the observation that dissolution of drug is influenced by temperature of crystallization.

\section{Characterization of drug and prepared crystals \\ Differential scanning calorimetric analysis}

The differential scanning calorimetry (DSC) thermograms of aceclofenac and prepared crystals are shown in the Fig. 6.

The DSC thermogram of aceclofenac showed an endothermic peak at $162.53^{\circ} \mathrm{C}$ with onset and endset temperatures of $153.16^{\circ} \mathrm{C}$ and $169.17^{\circ} \mathrm{C}$, respectively. The latent heat of fusion ( $\Delta \mathrm{H}$ fus) was found to be $-1.37 \mathrm{~J} / \mathrm{g}$, indicating crystalline nature of the drug. Similarly, the DSC thermogram of the prepared crystals in ethanol and acetone showed endothermic peak at $150.94^{\circ} \mathrm{C}$ and $154^{\circ} \mathrm{C}$ with onset and endset temperatures of $151.88^{\circ} \mathrm{C}, 152.07^{\circ} \mathrm{C}$ and $167.44^{\circ} \mathrm{C}, 169.99^{\circ} \mathrm{C}$, respectively. The latent heat of fusion ( $\Delta \mathrm{H}$ fus) was found to be $-1.37 \mathrm{~J} / \mathrm{g}$. The DSC thermogram of the prepared crystals in ethanol and acetone by ultrasonication showed an endothermic peak at $160^{\circ} \mathrm{C}$ and $160.73^{\circ} \mathrm{C}$ with onset and endset temperatures of $152.62^{\circ} \mathrm{C}$, $156.56^{\circ} \mathrm{C}$ and $166.38^{\circ} \mathrm{C}, 167.20^{\circ} \mathrm{C}$, respectively. The latent heat of fusion ( $\Delta \mathrm{H}$ fus) was found to be $-1.20 \mathrm{~J} / \mathrm{g}$. There was no appreciable change in the melting endotherm of prepared crystals compared to that of pure drug.

\section{$\mathrm{X}$-ray powder diffraction}

PXRD pattern of pure crystalline drug was shown in Fig. 7 and prepared crystals in the different solvent are shown in Fig. 8. In Fig. 7, characteristic intensity peak was found at $2 \theta$ range $7^{\circ}-55^{\circ}$. PXRD patterns of the prepared crystals at different temperature are shown in Fig. 7 and do not shows difference as compared to the pure crystalline drug which was showing same characteristic peak but the value of intensity peaks somewhat increases as compared to pure drug, this increases in intensity of peaks leads to do not conversion to amorphous form of the drug. The increases intensity of peak shows and does not change in crystal habit.

\section{Scanning electronic microscopy}

SEM micrographs of aceclofenac and prepared crystals are shown in the Fig. 9. The particle size decreases when the ultrasonic power is applied, because ultrasonication makes the mixture, which is composed of the antisolvent (water) and the main solution (acetone or ethanol) and more homogeneous. When the ultrasonic is applied, the distribution of supersaturation becomes more uniform, allowing local outbreaks of nucleation to be avoided. In addition, the introduction of ultrasonic irradiation accelerates the formation of crystal nuclei. The morphology of aceclofenac is improved after ultrasonic crystallization and the crystals are much smaller than pure drug. 


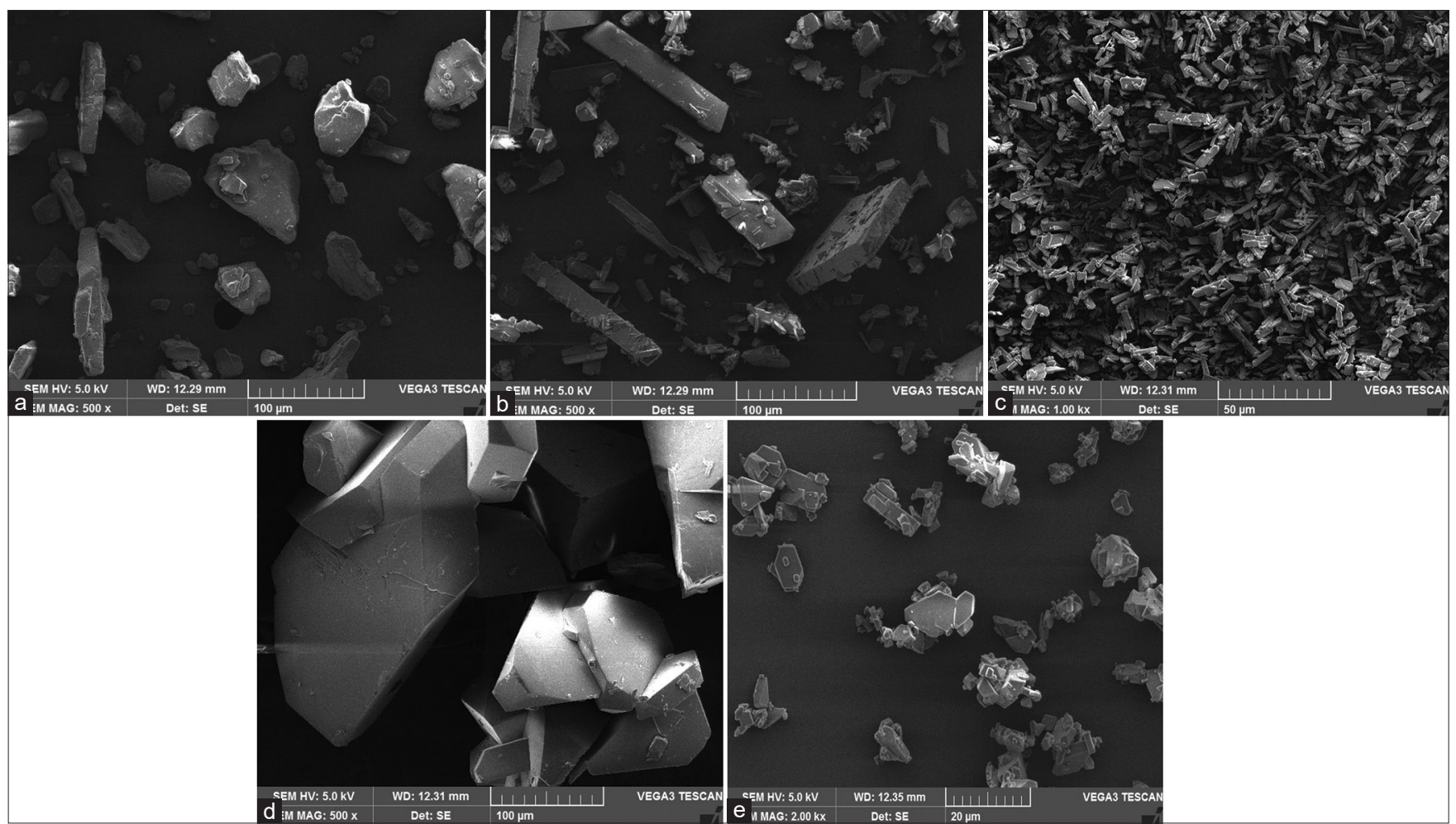

Fig. 9: Scanning electronic microscopy of (a) aceclofenac, (b) crystals prepared using ethanol, (c) crystals prepared in ethanol using sonication, (d) crystals prepared using acetone, and (e) crystals prepared in acetone using sonication

\section{REFERENCES}

1. Jagtap VA, Vidyasagar G, Dvivedi SC. Solubility enhancement of rosiglitazone by using melt sonocrystallization. J Ultr 2014;17:27-32.

2. Kumar S, Singh P. Various techniques for solubility enhancement. J Pharm Innov 2016;5:23-8.

3. Anderson NG. Practical Process Research and Development. $2^{\text {nd }}$ ed. New York: Academic Press; 2012. p. 329-59.

4. Peinado LS, Castro MD. The role ultrasound in pharmaceutical production: Sonocrystallization. J Pharm Pharmcol 2016;68:1249-67.

5. Park MW, Yeo SD. Antisolvent crystallization of roxitromycin and the effect of ultrasound. Sep Sci Technol 2010;45:1402-10.

6. Lonare AA, Patel SR. Antisolvent crystallization of poorly water soluble drugs. Int J Chem Eng Appl 2013;4:337-41.

7. Mahesh M, Harshal J, Anant P. Melt sonocrystallization of ibuprofen. Eur J Pharm Sci 2005;25:41-8.

8. Thenge RR. Crystal modification of aceclofenac by spherical crystallization to improve solubility dissolution rate and micromeritic properties. J Pharm Res 2012;5:9747.

9. Baek N, Oh GH, Park C, Tran T, Park YJ, Oh E, et al. Reprecipitation of poorly water-soluble cilostazol crystals using adsorbing carriers for enhanced dissolution and physicochemical modification. J Drug Del Sci Technol 2018;43:477-86.

10. Belkacem N, Salem MS, Alkhatib HS. Effect of ultrasound on the physico-chemical properties of poorly soluble drugs: Antisolvent sonocrystallization of ketoprofen. J Powder Tech 2015;285:16-24 